\title{
Variations in Precipitating Convective Feature Populations with ITCZ Width in the Pacific Ocean
}

\author{
KYLE R. WODZICKI AND ANITA D. RAPP \\ Department of Atmospheric Sciences, Texas A\&M University, College Station, Texas
}

(Manuscript received 14 September 2019, in final form 27 February 2020)

\begin{abstract}
Many recent studies have aimed to better understand changes in the characteristics of the intertropical convergence zone (ITCZ), including ITCZ location, width, and precipitation intensity. However, very few studies have looked at the relationship between characteristics of convection within the ITCZ and ITCZ width. The present work uses information from an ITCZ identification database and Tropical Rainfall Measuring Mission (TRMM) precipitation feature (PF) database to quantify variations in convective characteristics across the ITCZ in the Pacific Ocean. Data are partitioned into wide and narrow ITCZ regimes to quantify differences in convection between different ITCZ regimes. Under the wide regime, convection deeper than $5 \mathrm{~km}$, with areas greater than $100 \mathrm{~km}^{2}$, or stratiform rain fractions greater than 0.5 is, on average, $24 \%, 23 \%$, and $12 \%$ more frequent, respectively. In the narrow regime, the signal is reversed, with average increases in the frequency of convection with heights below $5 \mathrm{~km}$, areas less than $100 \mathrm{~km}^{2}$, or stratiform rain fractions less than 0.5 of $15 \%, 4 \%$, and $6 \%$, respectively. Positive and negative anomalies in columnar water vapor (CWV) and sea surface temperature (SST) across the ITCZ are observed in the wide and narrow regimes, respectively. There is also a strong positive correlation between an El Niño-Southern Oscillation (ENSO) index and ITCZ width anomalies, with wide (narrow) ITCZs occurring during warm (cold) phases of ENSO. This implies that the strengthening and weakening of the Walker circulation associated with ENSO may play a role in modulating the convective populations that contribute to the Pacific ITCZ width variations.
\end{abstract}

\section{Introduction}

The accurate prediction of changes in the hydrologic cycle is of great importance as water is essential for life. Shifts in the locations of the world's deserts and rain belts could spell disaster through loss of crops, property, and even life. In the tropics and extratropics, changes in the hydrologic cycle can broadly be linked to changes in the Hadley and Walker circulations. Numerous studies have aimed to quantify changes in the Hadley circulation in a warming climate using data from reanalyses (e.g., Mitas and Clement 2005; Stachnik and Schumacher 2011; Nguyen et al. 2013), general circulation models (e.g., Mitas and Clement 2006; Lu et al. 2007; Lau and Kim 2015; Su et al. 2014), and observations (e.g., Hu and Fu 2007; Seidel et al. 2008; Hu et al. 2011). There is disagreement between studies as to how the strength of the Hadley circulation has changed in recent decades ( $\mathrm{Hu}$ et al. 2018); however, the general consensus is that the Hadley circulation has expanded

Corresponding author: Kyle R. Wodzicki, wodzicki@tamu.edu poleward. While studies of changes in the future climate generally agree that the Hadley circulation will become weaker, Su et al. (2014) noted that the circulation goes through complex structure changes as the climate warms. Similar studies of the Walker circulation also disagree on the change of the circulation's strength; some found weakening and a westward shift (e.g., Tanaka et al. 2004; Vecchi et al. 2006; Power and Smith 2007; Schwendike et al. 2015), while others found strengthening (e.g., Meng et al. 2012; L'Heureux et al. 2013; Sohn et al. 2013). As the intertropical convergence zone (ITCZ) is the main driver of the Hadley circulation and influences the Walker circulation, changes in the intensity of convection within the ITCZ impact both of these circulations (Hack et al. 1989; Hou and Lindzen 1992; Dodd and James 1997; Webster 2004). Therefore, it is important to understand the link between broader ITCZ characteristics and the convective systems within the ITCZ.

One of the first major studies of the ITCZ's climatological location and seasonal migration used observations of highly reflective clouds to identify the ITCZ 
(Waliser and Gautier 1993), while more recent studies have applied statistical models to observations (Bain et al. 2011) and thresholding techniques to reanalysis data (Berry and Reeder 2014) to study the ITCZ. Building off the methods of Berry and Reeder (2014), Wodzicki and Rapp (2016) quantified the ITCZ width and precipitation intensity and determined that the ITCZ has been narrowing and intensifying over the past $30+$ years, possibly due to an increase in the frequency of midtropospheric dry layers (Bartos et al. 2018). Their findings are in line with other observational studies that noted long-term increases in tropical precipitation rate, mainly in the ITCZ region (Lau and Wu 2007; Zhou et al. 2011), and lend support to climate model predictions of further narrowing and intensification in the future (Lau et al. 2013; Lau and Kim 2015; Su et al. 2017, 2019). While the aforementioned studies focused on long-term trends in ITCZ characteristics, many studies have also noted a link between convective systems and ITCZ width variations at other time scales, from synoptic to interseasonal.

At synoptic time scales, Straub and Kiladis (2002) and Serra and Houze (2002) found that as Kelvin waves passed over a region, convection rapidly initiated and organized along the central axis of the ITCZ. This increase in organized convection widened the ITCZ, with the increase in ITCZ width propagating with convection associated with the Kelvin waves as they moved across the ocean basin. Serra and Houze (2002) also noted that the passage of Kelvin waves initiated hurricane development after which the ITCZ tends to completely break down, with deep convection disappearing and ITCZ width decreasing to near zero. A more recent study by Dias and Pauluis (2011) found a relationship between ITCZ location and width and the speed of convectively coupled Kelvin wave (CCKWs). They suggest that the meridional circulation associated with the CCKWs modulates ITCZ width and precipitation, indicating a link between the broader ITCZ width and the characteristics of the convective systems within.

Dias and Pauluis (2011) also noted that the ITCZ is abnormally wide during El Niño events in the central Pacific $\left(180^{\circ}-130^{\circ} \mathrm{W}\right)$, consistent with the observational findings of Wodzicki and Rapp $\left(2016,160^{\circ} \mathrm{E}-160^{\circ} \mathrm{W}\right)$. Simple Walker circulation models (e.g., Bretherton and Sobel 2002) also show a wider zone of convection when the sea surface temperature (SST) gradient across the Walker circulation weakens during El Niño. Insomuch as the ITCZ tends to be wide during El Niño and narrow during La Niña, some studies have indirectly looked at variations in characteristics of convection in different ITCZ width regimes. Masunaga et al. (2005) used Tropical Rainfall Measuring Mission (TRMM) satellite data to show that during El Niño events, deep stratiform and convective systems became much larger and more frequent, taking the place of shallow convection, when compared to La Niña. Henderson et al. (2018) found very similar changes from deep isolated systems in the La Niña phase to large, organized systems with increased stratiform rain area during El Niño. This is further supported by Stephens et al. (2018), who found evidence for the Bjerknes feedback in observations that show large positive latent and radiative heating perturbations with super-Clausius-Clapeyron precipitation responses in the warming, moistening ITCZ region during El Niño. However, it remains unclear how the population and character of convective clouds within the ITCZ vary to produce the observed precipitation and heating rate perturbations that feedback on these large-scale circulations as similar radiative and latent heating perturbations could come from very different cloud populations. There are some indications that the character of convective systems in the tropics may be shifting as the convective zones narrow at longer (decadal) time scales (Tan et al. 2015), but this has not been specifically analyzed in the context of expansion and contraction of the ITCZ at shorter (annual or seasonal) time scales.

The aim of the present study is to better understand the relationship between the variations in large-scale ITCZ width and characteristics of convection [e.g., rain rate (RR), maximum height, and stratiform/convective partitioning]. This will be done through the analysis of convective features located within the ITCZ based on the Pacific ITCZ identifications from Wodzicki and Rapp (2016). While previous studies have focused on long-term changes in ITCZ precipitation intensity and location, the relatively short TRMM data record limits the present study to shorter time scales. Thus, features in two different ITCZ width regimes (wide and narrow based on the upper and lower quartiles of the width distribution, respectively) are compared to understand the relationship between the distribution of convection characteristics and variations in ITCZ width.

\section{Data and methods}

Wodzicki and Rapp (2016) created an ITCZ climatology that provides information about the location, width, and RRs within the Pacific ITCZ $\left(160^{\circ} \mathrm{E}-100^{\circ} \mathrm{W}\right)$ on a monthly-mean time scale. To identify the ITCZ they used monthly 1000-850-hPa layer mean $u$ - and $v$-wind components to compute divergence, gradient of divergence, and Laplacian of divergence. Locations where the gradient of divergence equaled zero were taken as the first-guess ITCZ center, with the divergence 
and Laplacian of divergence fields used to mask out regions of divergence and relative minima in the divergence field, respectively. The $850-\mathrm{hPa}$ wet-bulb potential temperature was used as a final mask, limiting identifications to tropical regions. After the ITCZ center was identified, ITCZ boundaries were located by iterating from the ITCZ center to the north and south to find the latitude where RR fell below a threshold of $2.5 \mathrm{~mm} \mathrm{day}^{-1}$. While their work focused on long-term trends in ITCZ characteristics using long time series Global Precipitation Climatology Project (GPCP) RRs (Adler et al. 2003), the present study utilizes TRMM Microwave Imager (TMI) RRs for boundary identifications. The two major benefits of using TMI-based ITCZ identification over GPCP are 1) the TMI ITCZ climatology is already available from Wodzicki and Rapp (2016) and 2) the TMI sensor is on the TRMM satellite with the precipitation radar (PR), which is used to define convective features.

The TRMM satellite was launched in 1997 to further the understanding of precipitation in the tropics (Simpson et al. 1988; Kummerow et al. 1998). As the first satellite to feature a PR, TRMM provided invaluable information about internal precipitation structures, allowing for improved characterizations of precipitating convection in the tropics. However, with over 16 years of data, studying the distributions and morphology of precipitating systems using pixel-level data can be cumbersome. The work of Nesbitt et al. (2000) and Liu et al. (2008) greatly reduced data processing requirements through the development of a precipitation feature (PF) database. The current study uses their radar PF definition, defined as a single or contiguous group of PR pixels that have RRs greater than $0 \mathrm{~mm} \mathrm{~h}^{-1}$, because the convective characteristics used here to quantify convective intensity (i.e., maximum height reached by the PF, RR, area, and stratiform and convective partitioning) are all derived from the PR. It is worth noting that the spatial and temporal resolutions of radar PFs are highly variable as they are limited by the presence of rain and the spatial and temporal resolutions of TRMM. The relatively narrow swath width $(\sim 215 \mathrm{~km})$ of TRMM also limits the maximum size of PFs that can be sampled; however, Nesbitt et al. (2000) found that only $17 \%$ of PFs are affected and noted that while this does cause some truncation in the area distribution of $\mathrm{PFs}$, other characteristics remain unbiased. As convection can be greatly influenced by its environment (Derbyshire et al. 2004; Rapp et al. 2011; Hohenegger and Stevens 2013), it is advantageous to consider changes in convective characteristics with changes in the ITCZ environment.
To do this, PFs are matched to Remote Sensing Systems (RSS) TMI version 7 (Wentz 1997; Hilburn and Wentz 2008) data on a $0.25^{\circ} \times 0.25^{\circ}$ grid at daily resolution. PFs are matched to the closest possible TMI time and the nearest grid box using a nearest neighbor method based on the center latitude and longitude of an ellipse fitted to the PF (Liu 2013). Using the monthly ITCZ center and boundary locations, each PF and TMI grid box are assigned an ITCZ flag and a distance from the ITCZ center; PFs within the ITCZ are hereafter referred to as ITCZ PFs. The variables of interest in the present study are PF area, $\mathrm{RR}$, stratiform fraction, and maximum height, and TMI columnar water vapor (CWV) and SST. PF area is calculated by multiplying the number of pixels in the feature by the size of each pixel and the RR is average RR over the entire feature. To reduce bias, PFs with fewer than four pixels are excluded from the analysis as these very small, very frequent features can introduce noise (Nesbitt et al. 2000).

As previously discussed, modeling studies suggest a link between the width of the ITCZ and the characteristics of convection within the ITCZ (Chou and Neelin 2004; Neggers et al. 2007). Thus, we partition our data into wide and narrow ITCZ regimes where a wide (narrow) ITCZ is any ITCZ that has a deseasonalized zonal-mean width anomaly (\%) above (below) the 75th (25th) percentile of the ITCZ width anomaly distribution for the 17-yr period from December 1997 through September 2014. All analysis is also performed across the bulk of the Pacific basin from $160^{\circ} \mathrm{E}$ to $100^{\circ} \mathrm{W}$. The far eastern Pacific and far western Pacific are excluded to reduce the influence of spurious ITCZ identification in the North American monsoon region and the South Pacific convergence zone (SPCZ), respectively. While continental areas may be present in the northern and southern regions of the domain, any PFs over such areas are excluded so that only PFs over the ocean are considered.

Using the matched PF database, monthly zonal median values for $\mathrm{PF}$ area, maximum height, and $\mathrm{RR}$ are computed for $2.5^{\circ}$ bins centered on the ITCZ center. Median values are used as there tends to be many small and very few large PFs, which skews the mean values. These data are then deseasonalized to calculate percent anomalies. Using the deseasonalized anomalies from months above the upper and below the lower quartiles of the ITCZ width distribution, the average deviations from the mean state of the PF characteristics are determined. The significance of anomalies throughout the analysis are determined using a simple bootstrapping method wherein all deseasonalized anomalies are randomly resampled, with replacement, 10000 times. 

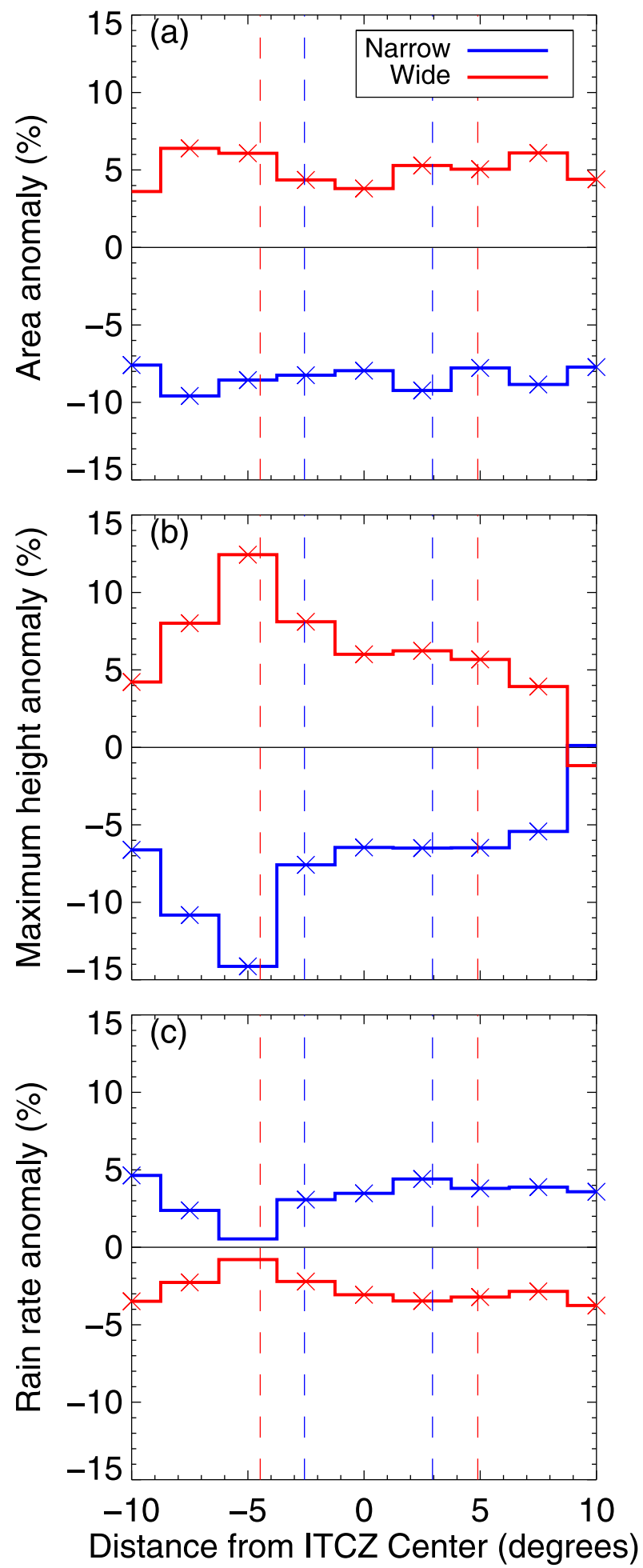

FIG. 1. Means of zonal median percent anomalies for (a) PF area, (b) maximum height reached by the PF, and (c) RR. Blue (red) lines correspond to months below the lower (above the upper) quartile of the ITCZ width distribution and $\times$ s indicate anomalies that are significantly different from zero at the $95 \%$ level. Distances are relative to the center of the ITCZ (positive north)
A sampling size of 50 is used because that is roughly one-quarter the number of months analyzed, giving a sample size equal to the number of months above (below) the upper (lower) quartile of the ITCZ width distribution. The average of each resample is computed, giving 10000 realizations of the mean anomalies. An anomaly is determined to be significant if it falls in the top or bottom $2.5 \%$ of the bootstrapped distribution, giving a two-tailed test at the $95 \%$ confidence level.

\section{Results}

\section{a. PF populations}

To gain a general understanding of the changes in convection in different ITCZ width regimes, Fig. 1 shows the average zonal anomalies with wide ITCZ months (above upper quartile) in red and narrow ITCZ months (below lower quartile) in blue. Anomalies that are significantly different from the mean at the $95 \%$ level are indicated with an " $X$ ". From Figs. 1a and 1b, PFs tend to be larger and deeper when the ITCZ is wide, with maximum heights $5 \%-14 \%$ higher than average across the ITCZ. RR shows a more interesting picture (Fig. 1c), with wide months having below average RRs across the ITCZ region while narrow months have above average RRs. While this seems at odds with previous studies that have shown RRs increasing as convection becomes larger and deeper (DeMott and Rutledge 1998; Nesbitt et al. 2006), this result is due to the use of conditional PF-averaged RR, not area-averaged RR, in the present study. As PFs become larger they will contain larger stratiform areas that tend to have a much lower instantaneous RR than small cumulus dominated by convective RRs. This acts to suppress the storm-averaged $\mathrm{RR}$, while area-averaged RR would still be above normal.

To gain a better sense of how the PF population differs between the narrow and wide ITCZ regimes, PFs are partitioned into cumulus, congestus, and cumulonimbus regimes, based on maximum height of the PF, using a slightly modified version of the definitions from Johnson et al. (1999) with bins of $0-5 \mathrm{~km}$ for cumulus, $5-10 \mathrm{~km}$ for congestus, and 10-20 km for cumulonimbus. Figure 2 shows the zonal distribution of clouds by fractional occurrence for cumulus, congestus, and cumulonimbus for narrow and wide months. It is worth noting that, on average, cumulus, congestus, and cumulonimbus clouds

and are in units of degrees. Vertical dashed lines show the mean location of the northern and southern ITCZ boundaries for the narrow and wide regimes. 

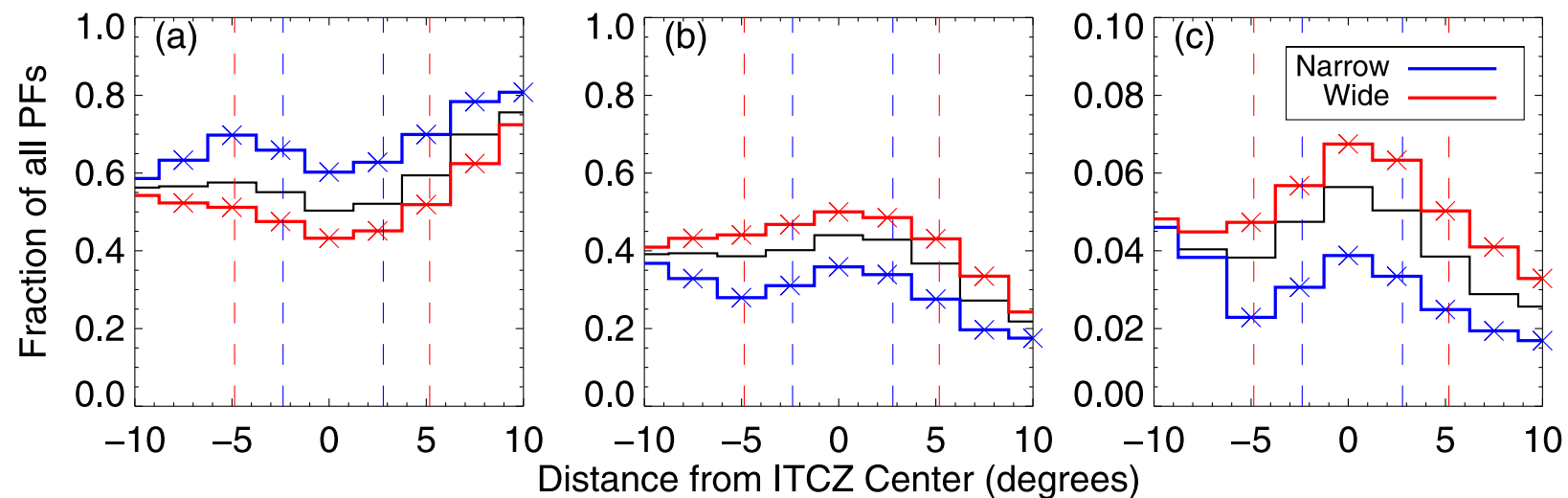

FIG. 2. Zonal fractions of PFs by type for (a) cumulus, (b) congestus, and (c) cumulonimbus. Blue (red) lines correspond to months below the lower (above the upper) quartile of the ITCZ width distribution, and $\times$ s indicate anomalies that are significantly different from the mean at the $95 \%$ level. Distances are relative to the center of the ITCZ (positive north) and are in units of degrees. Vertical dashed lines show the mean location of the northern and southern ITCZ boundaries for the narrow and wide regimes. The sum of all three histograms is unity.

generate roughly $7 \%, 27 \%$, and $67 \%$ of all rain, respectively, across the ITCZ. From this figure it is clear that most of the anomalies observed in Fig. 1 are due to differences in cumulus and congestus clouds, with cumulus (congestus) clouds occurring more frequently when the ITCZ is narrow (wide). Figure $2 \mathrm{c}$ shows that cumulonimbus are roughly $30 \%-50 \%$ more frequent in the wide regime than the narrow across the ITCZ; however, cumulonimbus account for a small percentage $(<10 \%)$ of all clouds. What is perhaps more interesting is that there are roughly the same number of clouds across the ITCZ during wide and narrow months (not shown), which means that as the ITCZ narrows cumulonimbus clouds become less frequent and there is a shift from congestus to cumulus, indicating a shift to shallow, weaker convection. Along with this shift in cloud frequency is a shift in the percent contribution to total rain in the wide (narrow) regime to $5 \%(10 \%)$ for cumulus, $24 \%(31 \%)$ for congestus, and $71 \%$ (59\%) for cumulonimbus.

\section{b. PF convection characteristics}

To further study the changes in PF characteristics in different ITCZ width regimes, joint histograms of PF characteristics are used. Figures 3 and 4 show joint histograms for PF maximum height and area, respectively.
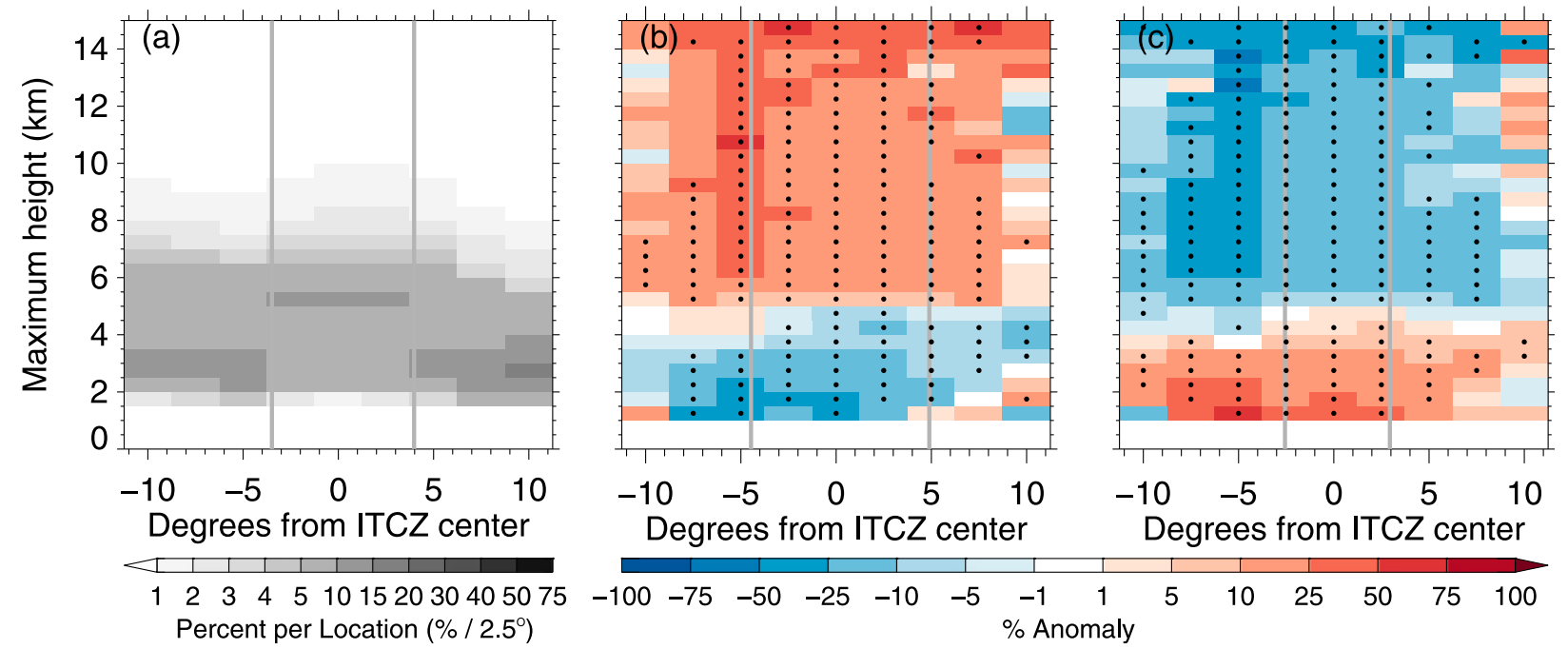

FIG. 3. Joint histograms of PF maximum height and distance from the center of the ITCZ for (a) climatology, (b) mean of monthly percent anomalies in wide ITCZ months, and (c) mean of monthly percent anomalies in narrow ITCZ months. Distances are relative to the center of the ITCZ (positive north) and are in units of degrees. The vertical gray lines in all panels represent the location of the ITCZ boundaries for each data subset. Stippling indicates anomalies that are significantly different from zero at the $95 \%$ level. 

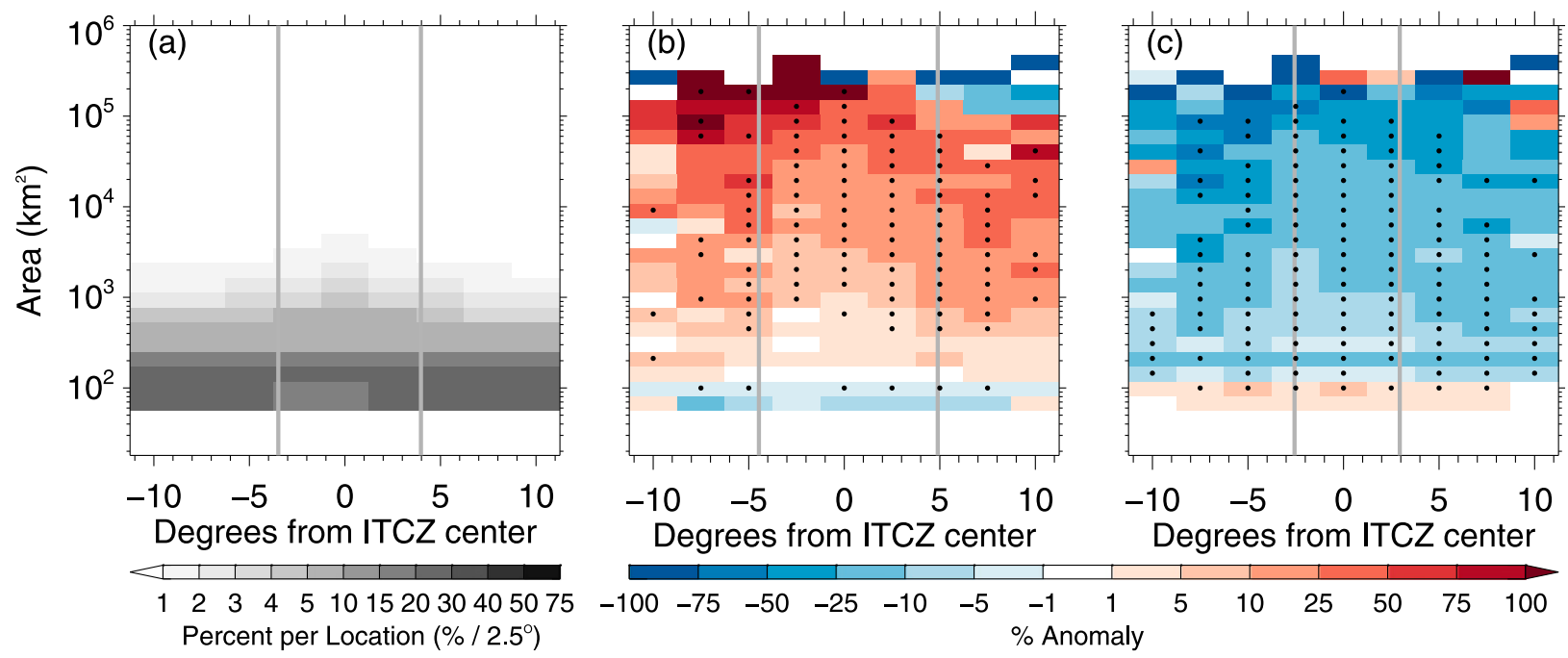

FIG. 4. As in Fig. 3, but for the PF area. Area bins are logarithmic. Note that only data before August 2001 are included in the smallest area bin $\left(\sim 55-81 \mathrm{~km}^{2}\right)$.

To create these figures, monthly joint histograms are generated for the entire TRMM period (December 1997 through September 2014), showing the frequency of PFs with a given characteristic (e.g., maximum height of $5 \mathrm{~km}$ ) at a given distance from the ITCZ center (e.g., $\left.\pm 1.25^{\circ}\right)$. Each monthly histogram is then scaled to show the percentage of PFs with a given attribute. Figure 3a shows the average distribution for all months where, as an example, $10 \%-15 \%$ of PFs that are $\pm 1.25^{\circ}$ from the ITCZ center have maximum heights of $5-5.5 \mathrm{~km}$. The monthly joint histograms are then deseasonalized and converted to percent anomalies using data from the full TRMM period. These anomalies are then averaged for months that fall above the upper (wide) and below the lower (narrow) quartiles of the ITCZ width distribution, with the average anomalies shown in Figs. $3 \mathrm{~b}$ and $4 \mathrm{~b}$ and in Figs $3 c$ and $4 c$, respectively. Vertical gray lines show the average locations of the ITCZ boundaries over the respective months of each panel and stippling in Figs $3 b, c$ and $4 b, c$ indicate significant departures from the mean state at the $95 \%$ level. Note that in Fig. 4, only data before August 2001 are included in the smallest area bin $\left(\sim 55-81 \mathrm{~km}^{2}\right)$ when computing means and anomalies because of the difference in pre- and postboost pixel sizes.

From Fig. 3a it is clear that the majority of PFs have heights between 2 and $8 \mathrm{~km}$, with the frequency of deeper storms (i.e., heights greater than $8 \mathrm{~km}$ ) increasing slightly toward the center of the ITCZ. On the northern edge of the ITCZ the distribution shifts to shallower PFs (i.e., heights less than $5 \mathrm{~km}$ ), with $20 \%-30 \%$ of PFs having heights around $3 \mathrm{~km}$ at $10^{\circ} \mathrm{N}$ of the ITCZ center. This is indicative of shallow cumulus in the subtropics; the ITCZ is typically located around $8^{\circ} \mathrm{N}$, placing the PFs around $15^{\circ}-20^{\circ} \mathrm{N}$. At the southern edge of the ITCZ, the picture is similar to that north of the ITCZ; however, PFs with heights greater than $6 \mathrm{~km}$ become more frequent, likely due to the SPCZ, or double ITCZ.

Looking at the anomalies in PF maximum height distribution for wide ITCZs (Fig. 3b) PFs with heights less than $4 \mathrm{~km}$ become less frequent across the domain, with increases in PFs taller than $4 \mathrm{~km}$. Note that some of the large increases occur near the southern boundary of the ITCZ. This suggests that when the ITCZ is wide, shallower convection is less common within the ITCZ and deep convection is more common, especially near the edges. For narrow ITCZs (Fig. 3c), PFs with heights below $4 \mathrm{~km}$ become much more frequent across the domain, with all PFs with heights greater than $4 \mathrm{~km}$ becoming less frequent. This indicates a general shift toward shallower convection when the ITCZ is narrow. Note that most of the bins within the ITCZ are stippled, indicating high confidence in these changes. However, outside of the ITCZ confidence diminishes (no stippling) suggesting a large spread in the anomalies observed.

Focusing now on variability in PF frequency based on PF area, Fig. 4 shows the joint histograms of PF area and distance from the ITCZ center. While the orbital boost of TRMM did cause a reduction in the frequency of very light rain detected by the PR (Liu et al. 2012), RRs greater than $1 \mathrm{~mm} \mathrm{~h}^{-1}$ are not significantly affected. As the current study neglects very small PFs, many PFs with very low RRs have already been excluded. PFs with RRs less than $1 \mathrm{~mm} \mathrm{~h}^{-1}$ actually make up a larger percentage of PFs after the boost $(\sim 20 \%)$ than before the boost 

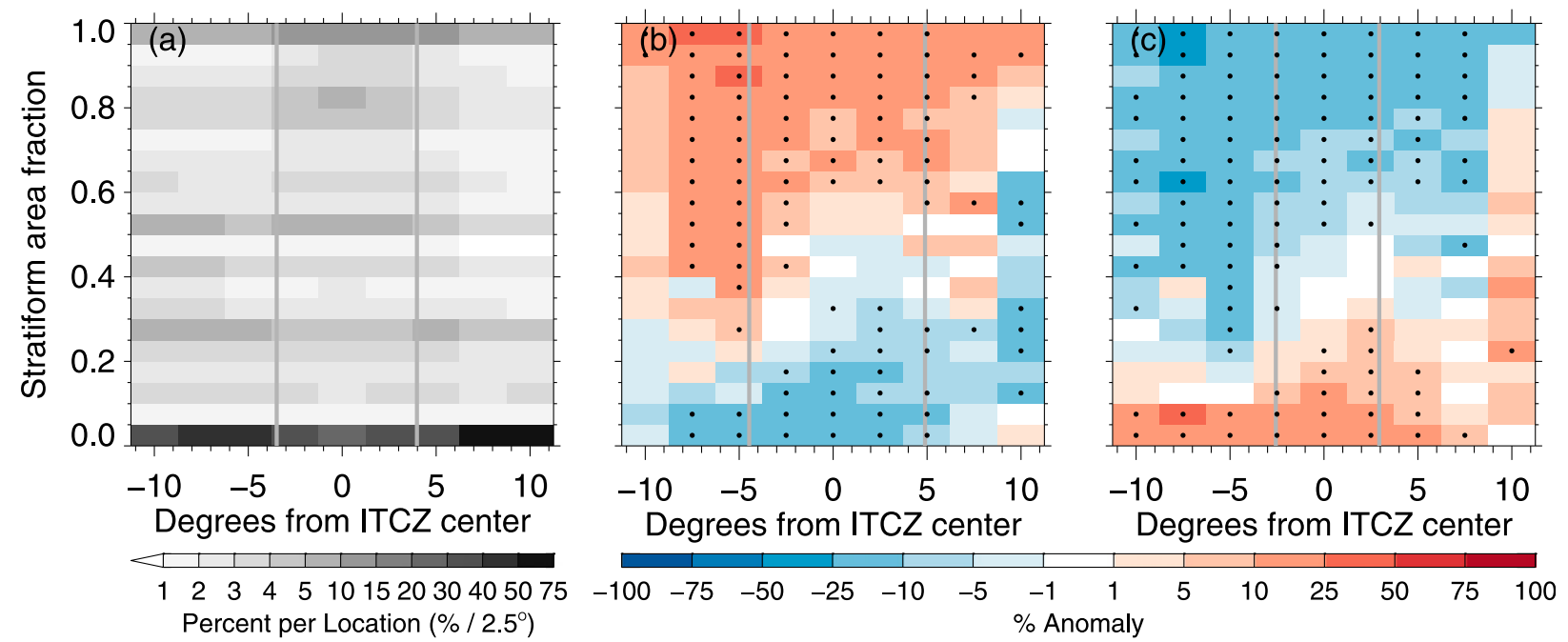

FIG. 5. As in Fig. 3, but for PF stratiform area fraction.

$(\sim 18 \%)$ and so the impact of the orbital boost is small. With PFs that have areas greater than $1000 \mathrm{~km}^{2}$ making up a small portion of the total distribution $(\sim 20 \%)$, small changes in the frequency of larger PFs lead to large percent changes; for example, if a $\mathrm{PF}$ of a given area appears only once in a given month's climatology but twice when the ITCZ is wide, a $100 \%$ increase in frequency will be observed.

Figure $4 \mathrm{~b}$ shows that when the ITCZ is wide, PFs with areas greater than $\sim 100 \mathrm{~km}^{2}$ become more frequent while PFs with areas less than $\sim 100 \mathrm{~km}^{2}$ become less frequent. Note that because the majority of PFs have areas less than $500 \mathrm{~km}^{2}$ a small percentage change in frequency can equate to a large number of PFs. From these anomalies a shift from cumulus (small and shallow) to congestus (moderately large and deep) and cumulonimbus (large and deep) features is apparent; however, the increases in the frequency of PFs with areas between 100 and $1000 \mathrm{~km}^{2}$ are not significant, indicating a large amount of variability in the frequency of PFs of this size. In contrast to the wide ITCZs, narrow ITCZs (Fig. 4c) show a reduction in PFs with areas greater than $\sim 100 \mathrm{~km}^{2}$, with increases in smaller PFs. This signifies a distinct shift toward smaller PFs in narrow ITCZs. To understand how PFs grow in the wide ITCZ regime, joint histograms of stratiform area fraction are created.

Stratiform area fraction is defined here as the number of PR pixels within a PF that are identified as stratiform rain by the 2A23 algorithm (Steiner et al. 1995; Awaka 1998) divided by the total number of PR pixels in the feature. Figure 5a shows the climatology of joint histograms of stratiform area fraction and distance from ITCZ center. PFs with very low stratiform area $(<5 \%)$ account for over $50 \%$ of all PFs across the entire ITCZ.
This is expected as congestus and cumulus type systems (i.e., convection that has little to no stratiform component) account for nearly all PFs (Fig. 2). As expected based on the shifts shown in PF area under wide ITCZs (Fig. 4b), Fig. 5b shows a shift toward PFs with predominantly stratiform rain when the ITCZ is wide, with Fig. 5c showing a shift toward predominantly convective rain when narrow. While it is not surprising that the stratiform area increases as PFs get larger, it is not immediately obvious why a wider ITCZ should be associated with larger, more organized individual storms.

\section{c. Environmental influences on PF populations}

Recent studies have shown a strong relationship between thermodynamics and precipitation over the ocean, with stratiform rain intensity and area being highly sensitive to water vapor above a critical value (Bretherton et al. 2004; Ahmed and Schumacher 2015). Therefore, it is possible that these different ITCZ regimes correspond to different large-scale thermodynamic variability associated with El Niño-Southern Oscillation (ENSO) or other large-scale drivers. As SST, CWV, and convection are all interconnected (Graham and Barnett 1987; Zhang 1993), TMI SST and CWV data are compared across the ITCZ for anomalously wide and narrow months.

All TMI grid boxes that contain at least one PF are used to create zonal median plots of SST and CWV for wide and narrow ITCZs (Fig. 6). While the differences are not large, both CWV and SST are significantly higher than average (at the 95\% level) across the ITCZ region when the ITCZ is wide. Bretherton et al. (2004, their Fig. 2a) shows that precipitation rates begin to pickup quickly above $50-\mathrm{mm}$ water vapor path, with rapid increases occurring above $55 \mathrm{~mm}$. While Ahmed and Schumacher (2015) used 

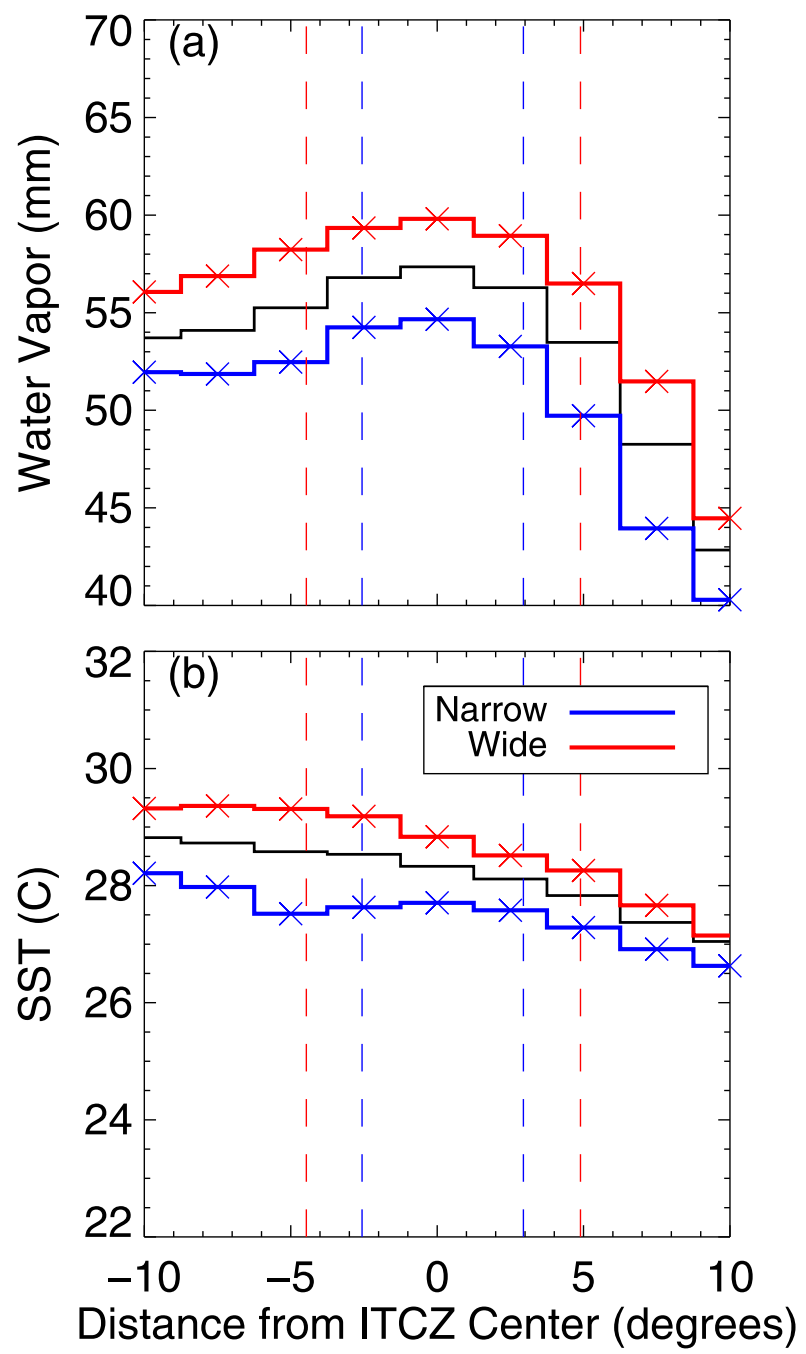

FIG. 6. Zonal median values of TMI (a) CWV and (b) SST. Blue (red) lines correspond to months below the lower (above the upper) quartile of the width distribution, and $\times$ marks indicate anomalies that are significantly different from zero at the $95 \%$ level. Distances are relative to the center of the ITCZ (positive north) and are in units of degrees. Vertical dashed lines show the mean location of the northern and southern ITCZ boundaries for the narrow and wide regimes.

column saturation fraction, a similar increase in stratiform RR was observed for very moist columns. Ahmed and Schumacher (2015) also noted that RR increases driven by changes in stratiform area were more pronounced than precipitation intensity changes. Thus, the changes in the morphology of PFs under the wide ITCZ regime are likely a result of increased moisture and SST over the tropics, either through increased evaporation locally or increased moisture convergence from remote sources. It is worth noting that near the northern boundary of the ITCZ CWV decreases rapidly, falling below the $48-\mathrm{mm}$ threshold defining the moist tropics

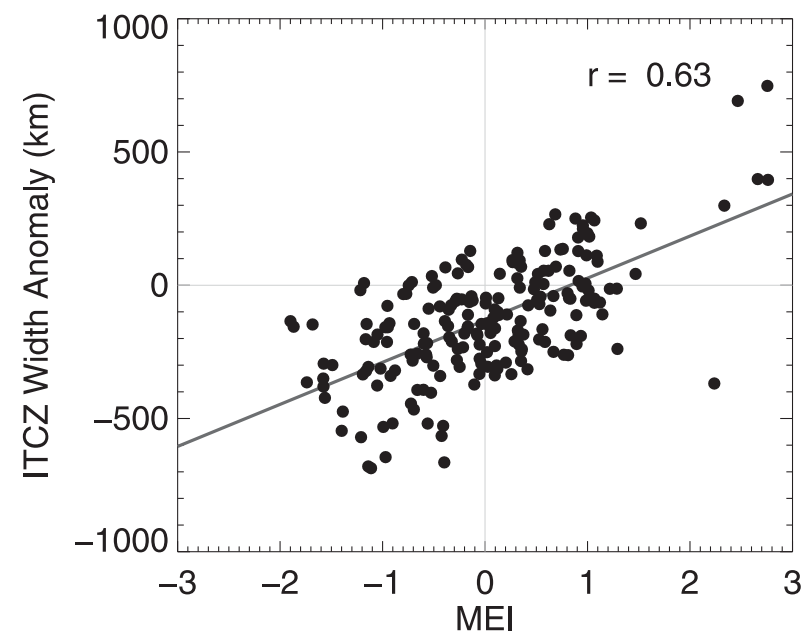

FIG. 7. Deseasonalized ITCZ width anomalies plotted against MEI for the entire TRMM period of December 1997-September 2014. The dark gray line is the least squares linear regression.

(Mapes et al. 2018) north of the ITCZ. However, at the southern boundary, CWV does not fall below $50 \mathrm{~mm}$, which we attribute to SPCZ influence in the central Pacific region. With ENSO being a major source of both SST and CWV variability in the Pacific (Rasmusson and Carpenter 1982; Trenberth et al. 2005), the relationship between ENSO on ITCZ width is examined.

Using the multivariate ENSO index (MEI; Wolter and Timlin 1993, 1998), the influence of ENSO on ITCZ width and PFs is determined by regressing MEI against the ITCZ width anomalies. As the MEI is a 2-month index, the value for a single month is computed by averaging the two surrounding 2-month values; that is, the MEI value for December is the average of the November/December and December/January values. Figure 7 indicates a strong relationship between monthly ITCZ width anomalies and ENSO, with a correlation coefficient of 0.63. Defining El Niño (La Niña) events as any month where the MEI is greater than 0.5 (less than -0.5 ) shows that 41 of the 50 anomalously wide ITCZ months occurred during an El Niño with 36 of the 50 anomalously narrow ITCZ months during a La Niña. However, we note that the patterns shown above also hold when we attempt to mitigate the ENSO influence by excluding ENSO events using the MEI thresholds defined above; general patterns remain similar, although the magnitude and significance of anomalies is greatly reduced.

\section{Summary and discussion}

TRMM PFs are used to study changes in the characteristics of convection within the ITCZ in the Pacific Ocean. Using the ITCZ climatology of 
Wodzicki and Rapp (2016), monthly ITCZ widths are partitioned into anomalously wide and narrow regimes, with the wide (narrow) regime consisting of months where percent anomalies of ITCZ width are above the upper (below the lower) quartile of the ITCZ width distribution.

PFs tend to be larger and deeper when the ITCZ is wide, with large increases in stratiform areas. While PF RRs are lower when the ITCZ is wide, this was determined to be a result of using conditional-average PF RR because PFs with large areas consist of mainly weakly raining stratiform clouds, which act to suppress stormaverage RR. The large increases in PF and stratiform area in the wide ITCZ regime may be linked to deep convection changes associated with SST and CWV increases based on a strong correlation between ITCZ width and the MEI and the anomalously high (low) SSTs and CWV in the wide (narrow) ITCZ width regime. This indicates a strong link between ITCZ width and PF characteristics to ENSO and the Walker circulation. While this may seem to be discrepant with model studies of the Walker circulation indicating that convection should be more intense during the contraction of the deep convection area (e.g., Bretherton and Sobel 2002), this analysis composites convection across the full longitudinal extent of the Pacific ITCZ. When the east-west temperature gradient is strong during La Niña, the ITCZ is narrow and the deeper, more intense convection is confined to a small portion of the averaging domain, so the composite convection is weaker when averaged across the longitudinal ITCZ extent. When the ITCZ is wide during El Niño as the east-west temperature gradient breaks down, the deep convection covers a larger fractional area of the ITCZ averaging domain. Studies of the relation between the strength of the Hadley circulation and the phases of ENSO also lend support to the current study's findings, with many studies (e.g., Oort and Yienger 1996; Stachnik and Schumacher 2011; Nguyen et al. 2013; Hu et al. 2018) showing an anticorrelation between the Hadley circulation and ENSO. This means that under El Niño (La Niña), when the ITCZ is wide (narrow), the Hadley circulation is narrow (wide).

The observed shift from shallow to deep convection between La Niña and El Niño coupled with the modulation of the Walker circulation also provides a mechanism for the large latent and radiative heating perturbations shown in models and observations (Rädel et al. 2016; Stephens et al. 2018). The increase in upperlevel cloud is the result of the shift from congestus across the bulk of the ITCZ in the narrow regime to larger systems with more widespread stratiform areas in the wide ITCZ regime. The expansion of more organized systems with large stratiform rain regions across the ITCZ during El Niño provide the large positive latent heating anomalies in the warming and moistening regions of the tropics that can feedback on the large-scale circulation.

It is clear from this analysis that variations in ITCZ width and PFs at interseasonal and interannual time scales may not be a good proxy for examining the relationship between convection characteristics and longterm ITCZ width variations due to changes in the Hadley circulation. This is likely due to the differences in the spatial and temporal scales as well as the complex balance of net energy input, atmospheric energy transport, ENSO, and Hadley and Walker circulation influences that drive changes in the Pacific ITCZ at different time scales (Adam et al. 2016).

More work is needed to unravel the connections between the convection distribution and the large-scale ITCZ state. Further efforts will also be focused on determining a proxy for the changes in convective characteristics observed in the present study that can be applied to long-time series reanalysis and model datasets to determine whether the relationship between the large-scale ITCZ characteristics and the convective systems within the ITCZ hold at longer time scales.

Acknowledgments. This research was partially supported by NASA Grants NNX13AG91G and NNX15AD13G. K. Wodzicki also acknowledges support for this work from the Texas A\&M Hagler Institute for Advanced Study. The Pacific ITCZ mask dataset is available from the Texas Data Digital Repository at https://doi.org/10.18738/T8/T5PH8N and the TRMM Precipitation Feature Database is available at http://atmos.tamucc.edu/trmm/. TMI data are produced by Remote Sensing Systems and sponsored by the NASA Earth Science MEaSUREs DISCOVER Project. Data are available at www.remss.com.

\section{REFERENCES}

Adam, O., T. Bischoff, and T. Schneider, 2016: Seasonal and interannual variations of the energy flux equator and ITCZ. Part II: Zonally varying shifts of the ITCZ. J. Climate, 29, 7281-7293, https://doi.org/10.1175/JCLI-D-15-0710.1.

Adler, R. F., and Coauthors, 2003: The version-2 Global Precipitation Climatology Project (GPCP) monthly precipitation analysis (1979-present). J. Hydrometeor., 4, 1147-1167, https://doi.org/ 10.1175/1525-7541(2003)004<1147:TVGPCP $>2.0$.CO;2.

Ahmed, F., and C. Schumacher, 2015: Convective and stratiform components of the precipitation-moisture relationship. Geophys. Res. Lett., 42, 10 453-10 462, https://doi.org/ 10.1002/2015GL066957.

Awaka, J., 1998: Early results on rain type classification by the Tropical Rainfall Measuring Mission (TRMM) Precipitation Radar. Proc. Eighth URSI Commission F Open Symp., Aveiro, Portugal, Union Radio Scientifique Internationale, 143-146.

Bain, C. L., J. De Paz, J. Kramer, G. Magnusdottir, P. Smyth, H. Stern, and C. Wang, 2011: Detecting the ITCZ in instantaneous satellite 
data using spatiotemporal statistical modeling: ITCZ climatology in the east Pacific. J. Climate, 24, 216-230, https://doi.org/10.1175/ 2010JCLI3716.1.

Bartos, E. A., A. D. Rapp, and K. R. Wodzicki, 2018: Increasing frequency of midtropospheric dry layers in the Pacific intertropical convergence zone. Geophys. Res. Lett., 45, 13 523-13 529, https://doi.org/10.1029/2018GL080799.

Berry, G., and M. J. Reeder, 2014: Objective identification of the intertropical convergence zone: Climatology and trends from the ERA-Interim. J. Climate, 27, 1894-1909, https://doi.org/ 10.1175/JCLI-D-13-00339.1.

Bretherton, C. S., and A. H. Sobel, 2002: A simple model of a convectively coupled Walker circulation using the weak temperature gradient approximation. J. Climate, 15, 2907-2920, https://doi.org/10.1175/1520-0442(2002)015\% 3C2907:ASMOAC\%3E2.0.CO;2.

- M. E. Peters, and L. E. Back, 2004: Relationships between water vapor path and precipitation over the tropical oceans. J. Climate, 17, 1517-1528, https://doi.org/10.1175/1520-0442(2004)017<1517: RBWVPA $>2.0 . \mathrm{CO} ; 2$

Chou, C., and J. D. Neelin, 2004: Mechanisms of global warming impacts on regional tropical precipitation. J. Climate, 17, 2688-2701, https://doi.org/10.1175/1520-0442(2004)017<2688: $\mathrm{MOGWIO}>2.0 . \mathrm{CO} ; 2$.

DeMott, C. A., and S. A. Rutledge, 1998: The vertical structure of TOGA COARE convection. Part I: Radar echo distributions. J. Atmos. Sci., 55, 2730-2747, https://doi.org/10.1175/ 1520-0469(1998)055<2730:TVSOTC >2.0.CO;2.

Derbyshire, S. H., I. Beau, P. Bechtold, J. Y. Grandpeix, J. L. Redelsperger, and P. M. M. Soares, 2004: Sensitivity of moist convection to environmental humidity. Quart. J. Roy. Meteor. Soc., 130, 3055-3079, https://doi.org/10.1256/qj.03.130.

Dias, J., and O. Pauluis, 2011: Modulations of the phase speed of convectively coupled Kelvin waves by the ITCZ. J. Atmos. Sci., 68, 1446-1459, https://doi.org/10.1175/2011JAS3630.1.

Dodd, J., and I. James, 1997: The impact of latent-heat release on the Hadley circulation. Quart. J. Roy. Meteor. Soc., 123, 1763-1770, https://doi.org/10.1002/qj.49712354215.

Graham, N., and T. Barnett, 1987: Sea surface temperature, surface wind divergence, and convection over tropical oceans. Science, 238, 657-659, https://doi.org/10.1126/science.238.4827.657.

Hack, J. J., W. H. Schubert, D. E. Stevens, and H.-C. Kuo, 1989: Response of the Hadley circulation to convective forcing in the ITCZ. J. Atmos. Sci., 46, 2957-2973, https://doi.org/ 10.1175/1520-0469(1989)046<2957:ROTHCT >2.0.CO;2.

Henderson, D. S., C. D. Kummerow, and W. Berg, 2018: ENSO influence on TRMM tropical oceanic precipitation characteristics and rain rates. J. Climate, 31, 3979-3998, https:// doi.org/10.1175/JCLI-D-17-0276.1.

Hilburn, K. A., and F. J. Wentz, 2008: Intercalibrated passive microwave rain products from the Unified Microwave Ocean Retrieval Algorithm (UMORA). J. Appl. Meteor. Climatol., 47, 778-794, https://doi.org/10.1175/2007JAMC1635.1.

Hohenegger, C., and B. Stevens, 2013: Preconditioning deep convection with cumulus congestus. J. Atmos. Sci., 70, 448-464, https://doi.org/10.1175/JAS-D-12-089.1.

Hou, A. Y., and R. S. Lindzen, 1992: The influence of concentrated heating on the Hadley circulation. J. Atmos. Sci., 49, 1233-1241, https://doi.org/10.1175/1520-0469(1992)049<1233: $\mathrm{TIOCHO}>2.0 . \mathrm{CO} ; 2$

Hu, Y., and Q. Fu, 2007: Observed poleward expansion of the Hadley circulation since 1979. Atmos. Chem. Phys., 7, 52295236, https://doi.org/10.5194/acp-7-5229-2007.
— C. Zhou, and J. Liu, 2011: Observational evidence for poleward expansion of the Hadley circulation. Adv. Atmos. Sci., 28, 33-44, https://doi.org/10.1007/s00376-010-0032-1.

- , H. Huang, and C. Zhou, 2018: Widening and weakening of the Hadley circulation under global warming. Sci. Bull., 63, 640-644, https://doi.org/10.1016/j.scib.2018.04.020.

Johnson, R. H., T. M. Rickenbach, S. A. Rutledge, P. E. Ciesielski, and W. H. Schubert, 1999: Trimodal characteristics of tropical convection. J. Climate, 12, 2397-2418, https://doi.org/10.1175/ 1520-0442(1999)012<2397:TCOTC >2.0.CO;2.

Kummerow, C., W. Barnes, T. Kozu, J. Shiue, and J. Simpson, 1998: The Tropical Rainfall Measuring Mission (TRMM) sensor package. J. Atmos. Oceanic Technol., 15, 809-817, https://doi.org/ 10.1175/1520-0426(1998)015<0809:TTRMMT>2.0.CO;2.

Lau, K.-M., and H.-T. Wu, 2007: Detecting trends in tropical rainfall characteristics, 1979-2003. Int. J. Climatol., 27, 979-988, https:// doi.org/10.1002/joc.1454.

Lau, W. K.-M., and K.-M. Kim, 2015: Robust Hadley circulation changes and increasing global dryness due to $\mathrm{CO}_{2}$ warming from CMIP5 model projections. Proc. Natl. Acad. Sci. USA, 112, 3630-3635, https://doi.org/10.1073/pnas.1418682112.

_ , H.-T. Wu, and K.-M. Kim, 2013: A canonical response of precipitation characteristics to global warming from CMIP5 models. Geophys. Res. Lett., 40, 3163-3169, https://doi.org/ $10.1002 / g r l .50420$.

L'Heureux, M., S. Lee, and B. Lyon, 2013: Recent multidecadal strengthening of the Walker circulation across the tropical Pacific. Nat. Climate Change, 3, 571-576, https://doi.org/ 10.1038/nclimate1840.

Liu, C., 2013: University of Utah TRMM precipitation and cloud feature database description version 2.0. Tech. Rep., University of Utah, Salt Lake City, UT, 33 pp.

—, E. J. Zipser, D. J. Cecil, S. W. Nesbitt, and S. Sherwood, 2008: A cloud and precipitation feature database from nine years of TRMM observations. J. Appl. Meteor. Climatol., 47, 2712-2728, https://doi.org/10.1175/2008JAMC1890.1.

Liu, X., Y. Fu, and Q. Liu, 2012: Significant impacts of the TRMM satellite orbit boost on climatological records of tropical precipitation. Chin. Sci. Bull., 57, 4627-4634, https://doi.org/ 10.1007/s11434-012-5357-y.

Lu, J., G. A. Vecchi, and T. Reichler, 2007: Expansion of the Hadley cell under global warming. Geophys. Res. Lett., 34, L06805, https://doi.org/10.1029/2006GL028443.

Mapes, B. E., E. S. Chung, W. M. Hannah, H. Masunaga, A. J. Wimmers, and C. S. Velden, 2018: The meandering margin of the meteorological moist tropics. Geophys. Res. Lett., 45, 1177-1184, https://doi.org/10.1002/2017GL076440.

Masunaga, H., T. S. L'Ecuyer, and C. D. Kummerow, 2005 Variability in the characteristics of precipitation systems in the tropical Pacific. Part I: Spatial structure. J. Climate, 18, 823-840, https://doi.org/10.1175/JCLI-3304.1.

Meng, Q., M. Latif, W. Park, N. S. Keenlyside, V. A. Semenov, and T. Martin, 2012: Twentieth century Walker circulation change: Data analysis and model experiments. Climate Dyn., 38, 1757-1773, https://doi.org/10.1007/s00382-011-1047-8.

Mitas, C. M., and A. Clement, 2005: Has the Hadley cell been strengthening in recent decades? Geophys. Res. Lett., 32, L03809, https://doi.org/10.1029/2004GL021765.

— and — 2006: Recent behavior of the Hadley cell and tropical thermodynamics in climate models and reanalyses. Geophys. Res. Lett., 33, L01810, https://doi.org/10.1029/2005GL024406.

Neggers, R. A., J. D. Neelin, and B. Stevens, 2007: Impact mechanisms of shallow cumulus convection on tropical climate 
dynamics. J. Climate, 20, 2623-2642, https://doi.org/10.1175/ JCLI4079.1.

Nesbitt, S. W., E. J. Zipser, and D. J. Cecil, 2000: A census of precipitation features in the tropics using TRMM: Radar, ice scattering, and lightning observation. J. Climate, 13, 4087-4106, https://doi.org/10.1175/1520-0442(2000)013<4087: ACOPFI $>2.0 . \mathrm{CO} ; 2$.

_, R. Cifelli, and S. A. Rutledge, 2006: Storm morphology and rainfall characteristics of TRMM precipitation features. Mon. Wea. Rev., 134, 2702-2721, https://doi.org/10.1175/MWR3200.1.

Nguyen, H., A. Evans, C. Lucas, I. Smith, and B. Timbal, 2013: The Hadley circulation in reanalyses: Climatology, variability, and change. J. Climate, 26, 3357-3376, https://doi.org/10.1175/ JCLI-D-12-00224.1.

Oort, A. H., and J. J. Yienger, 1996: Observed interannual variability in the Hadley circulation and its connection to ENSO. J. Climate, 9, 2751-2767, https://doi.org/10.1175/ 1520-0442(1996)009\%3C2751:OIVITH\%3E2.0.CO;2.

Power, S. B., and I. N. Smith, 2007: Weakening of the Walker circulation and apparent dominance of El Niño both reach record levels, but has ENSO really changed? Geophys. Res. Lett., 34, L18702, https://doi.org/10.1029/2007GL030854.

Rädel, G., T. Mauritsen, B. Stevens, D. Dommenget, D. Matei, K. Bellomo, and A. Clement, 2016: Amplification of El Niño by cloud longwave coupling to atmospheric circulation. Nat. Geosci., 9, 106-110, https://doi.org/10.1038/ngeo2630.

Rapp, A. D., C. D. Kummerow, and L. Fowler, 2011: Interactions between warm rain clouds and atmospheric preconditioning for deep convection in the tropics. J. Geophys. Res., 116, D23210, https://doi.org/10.1029/2011JD016143.

Rasmusson, E. M., and T. H. Carpenter, 1982: Variations in tropical sea surface temperature and surface wind fields associated with the Southern Oscillation/El Niño. Mon Wea. Rev., 110, 354-384, https://doi.org/10.1175/1520-0493(1982) 110\%3C0354:VITSST\%3E2.0.CO;2.

Schwendike, J., G. J. Berry, M. J. Reeder, C. Jakob, P. Govekar, and R. Wardle, 2015: Trends in the local Hadley and local Walker circulations. J. Geophys. Res. Atmos., 120, 7599-7618, https://doi.org/10.1002/2014JD022652.

Seidel, D. J., Q. Fu, W. J. Randel, and T. J. Reichler, 2008: Widening of the tropical belt in a changing climate. Nat. Geosci., 1, 21-24, https://doi.org/10.1038/ngeo.2007.38.

Serra, Y. L., and R. A. Houze Jr., 2002: Observations of variability on synoptic timescales in the east Pacific ITCZ. J. Atmos. Sci., 59, 1723-1743, https://doi.org/10.1175/15200469(2002)059<1723:OOVOST >2.0.CO;2.

Simpson, J., R. F. Adler, and G. R. North, 1988: A proposed Tropical Rainfall Measuring Mission (TRMM) satellite. Bull. Amer. Meteor. Soc., 69, 278-295, https://doi.org/10.1175/15200477(1988)069<0278:APTRMM>2.0.CO;2.

Sohn, B. J., S. W. Yeh, J. Schmetz, and H. J. Song, 2013: Observational evidences of Walker circulation change over the last 30 years contrasting with GCM results. Climate Dyn., 40, 1721-1732, https://doi.org/10.1007\%2Fs00382012-1484-z.

Stachnik, J. P., and C. Schumacher, 2011: A comparison of the Hadley circulation in modern reanalyses. J. Geophys. Res., 116, D22102, https://doi.org/10.1029/2011JD016677.

Steiner, M., R. A. Houze Jr., and S. E. Yuter, 1995: Climatological characterization of three-dimensional storm structure from operational radar and rain gauge data. J. Appl. Meteor., 34, 1978-2007, https://doi.org/10.1175/1520-0450(1995)034<1978: CCOTDS $>2.0 . \mathrm{CO} ; 2$.
Stephens, G. L., and Coauthors, 2018: Regional intensification of the tropical hydrological cycle during ENSO. Geophys. Res. Lett., 45, 4361-4370, https://doi.org/10.1029/2018GL077598.

Straub, K. H., and G. N. Kiladis, 2002: Observations of a convectively coupled Kelvin wave in the eastern Pacific ITCZ. J. Atmos. Sci., 59, 30-53, https://doi.org/10.1175/15200469(2002)059<0030:OOACCK > 2.0.CO;2.

Su, H., J. H. Jiang, C. Zhai, T. J. Shen, J. D. Neelin, G. L. Stephens, and Y. L. Yung, 2014: Weakening and strengthening structures in the Hadley circulation change under global warming and implications for cloud response and climate sensitivity. J. Geophys. Res. Atmos., 119, 5787-5805, https://doi.org/10.1002\%2F2014JD021642.

, and Coauthors, 2017: Tightening of tropical ascent and high clouds key to precipitation change in a warmer climate. Nat. Commun., 8, 15771, https://doi.org/10.1038/NCOMMS15771.

_ C. Zhai, J. H. Jiang, L. Wu, J. D. Neelin, and Y. L. Yung, 2019: A dichotomy between model responses of tropical ascent and descent to surface warming. npj Climate Atmos. Sci., 2, https://doi.org/10.1038/s41612-019-0066-8.

Tan, J., C. Jakob, W. B. Rossow, and G. Tselioudis, 2015: Increases in tropical rainfall driven by changes in frequency of organized deep convection. Nature, 519, 451-454, https://doi.org/10.1038/ nature14339.

Tanaka, H. L., N. Ishizaki, and A. Kitoh, 2004: Trend and interannual variability of Walker, monsoon and Hadley circulations defined by velocity potential in the upper troposphere. Tellus, 56A, 250-269, https://doi.org/10.3402/tellusa.v56i3.14410.

Trenberth, K. E., J. Fasullo, and L. Smith, 2005: Trends and variability in column-integrated atmospheric water vapor. Climate Dyn., 24, 741-758, https://doi.org/10.1007/s00382-005-0017-4.

Vecchi, G. A., B. J. Soden, A. T. Wittenberg, I. M. Held, A. Leetmaa, and M. J. Harrison, 2006: Weakening of tropical Pacific atmospheric circulation due to anthropogenic forcing. Nature, 441, 73-76, https://doi.org/10.1038/nature04744.

Waliser, D. E., and C. Gautier, 1993: A satellite-derived climatology of the ITCZ. J. Climate, 6, 2162-2174, https://doi.org/ 10.1175/1520-0442(1993)006<2162:ASDCOT>2.0.CO;2.

Webster, P. J., 2004: The elementary Hadley circulation. The Hadley Circulation: Present, Past, and Future, H. F. Diaz and R. S. Bradley, Eds., Kluwer Academic, 9-60.

Wentz, F. J., 1997: A well-calibrated ocean algorithm for Special Sensor Microwave/Imager. J. Geophys. Res., 102, 8703-8718, https://doi.org/10.1029/96JC01751.

Wodzicki, K., and A. Rapp, 2016: Long-term characterization of the Pacific ITCZ using TRMM, GPCP, and ERA-Interim. J. Geophys. Res., 121, 3153-3170, https://doi.org/10.1002\% 2F2015JD024458.

Wolter, K., and M. S. Timlin, 1993: Monitoring ENSO in COADS with a seasonally adjusted principal component index. Proc. 17th Climate Diagnostics Workshop, Norman, OK, NOAA, 52-57, http://www.esrl.noaa.gov/psd/enso/mei/WT1.pdf.

, and - 1998: Measuring the strength of ENSO events: How does 1997/98 rank? Weather, 53, 315-324, https://doi.org/ 10.1002/j.1477-8696.1998.tb06408.x.

Zhang, C., 1993: Large-scale variability of atmospheric deep convection in relation to sea surface temperature in the tropics. J. Climate, 6, 1898-1913, https://doi.org/10.1175/1520-0442(1993) 006\%3C1898:LSVOAD\%3E2.0.CO;2.

Zhou, Y., K.-M. Xu, Y. Sud, and A. Betts, 2011: Recent trends of the tropical hydrological cycle inferred from Global Precipitation Climatology Project and International Satellite Cloud Climatology Project data. J. Geophys. Res., 116, D09101, https://doi.org/10.1029/2010JD015197. 